\title{
Laboratory and field studies of some entomological aspects of the canine dirofilariasis problem in Japan ${ }^{1)}$
}

\author{
By
}

\author{
Hugh L. Keegan, William W. Betchley, Thomas B. Haberkorn, \\ Artson Y. Nakasone, Hideyo Sugiyama and Robert J. Warne2)
}

\section{INTRODUCTIGN}

In Japan, as in many areas where canine dirofilariasis occurs, little has been done to determine the true importance as vectors of indigenous mosquito species assumed to be involved in the epidemiology of this disease. The studies reported in this paper were conducted to obtain at least a small amount of basic entomological information on dirofilariasis in Japan. Specific objectives were to determine: (1) Dirofilaria immitis infection rates among individuals of seven species of culicine mosquitoes, and one anopheline species allowed to feed on infected dogs in the laboratory; (2) Whether there was a correlation between age of the host mosquito and either infectivity rate with $D$. immitis or development of the parasite in the intermediate host; (3) Effects, if any, of treatment of an infected dog with a filaricidal drug on infectivity of microfilariae in the dogs' blood for mosquitoes, or on subsequent development of $D$. immitis larvae in the mosquito host ; (4) Correlation of experimental infection rate data found in laboratory studies with $D$. immitis infection rates

1) Centribution from the Departments of Entomology and Veterinary Medicine of the 406th Medical Laboratory, U. S. Army Medical Command, Japan, APO San Francisco 96343. These studies were supported financially by the U. S. Army Medical Research and Development Command, Office of The Surgeon General, Washington, D. C.

2) Respectively : Colonel, U. S. Army (Present address: Department of Preventive Medicine, Medical Field Service School, Brooke Army Medical Center, Fort Sam Houston, Texas) ; SSG, Medical Laboratory Specialist ; SP 5, Medical Laboratory Specialist ; SP 5, Zoological Technologist, and Major, U. S. Army, Chief, Department of Veterinary Medicine, 406th Medical Laboratory.

The views of the authors do not purport to reflect the position of the Department of the Army. in mosquitoes captured and dissected in the field in a region of high endemicity for dirofilariasis.

\section{MATERIALS AND METHODS}

All mosquitoes used in feeding experiments were from colonies maintained at the 406th Medical Laboratory. The eight species involved were: Aedes aegypti, Aedes albopictus, Aedes togoi, Anopheles sinensis, Armigeres subalbatus, Culex fatigans, Culex pipiens pallens, and Culex tritaeniorhynchus. The Aedes aegypti were of the "Denken" strain obtained from the Institute for Infectious Diseases, University of Tokyo and had originally been established with specimens from the United States. The Culex fatigans colony had been established with specimens collected at Naha, Okinawa. The remainder of the colonies had been established with material from Japan. One of these, the $C$. tritaeniorhynchus colony, had been maintained continuously at the 406th Medical Laboratory since 1956.

Adult mosquitoes used in feeding experiments were held in 18 inch square screened cages. The single experimental feeding on a dog was the only blood meal for each mosquito. Additional nourishment was provided by sliced apples suspended on a wire, and by sugar water in a soaked cotton pad placed on top of each cage. Temperature in the insectary varied from $75-80$ degrees F. Humidity fluctuated from $70-80 \%$.

In most cases an 18 inch square cage was used for feeding mosquitoes on dogs. The top and three of the sides of the cage were screened. The bottom was of plywood, and the front of the cage was covered with a stockinet sleeve. During feeding periods the shaven hind quarters of the dog were placed in the cage. Feeding periods for each of the three species of Aedes, Armigeres subalbatus, and Culex tritaeniorhynchus commenced at 1330 hours and were of 
30-60 minutes duration. Specimens of Culex fatigans, Culex pipiens pallens, and Anopheles sinensis, which showed a marked reluctance to feed during the daytime, were given overnight feedings. This was done by holding the dog in a small animal cage which was placed inside a larger screened cage. Overnight feedings commended at 1630 hours and terminated at 0800 the next morning. Starting and finishing hours were chosen only because they coincided with duty hours of insectary personnel. At the end of the feeding period engorged mosquitces were removed and held in the 18 inch square cages previously described for 12 days. At the end of this period the mosquitoes were dissected and examined for presence of Dirofilaria immitis larvae. Dissection technique was as described by Kartman (1953) except that the saline used was lightly tinted with methylene blue. Records were kept of the number and location of $D$. immitis larvae in each mosquito.

The single treated dog used in feeding experiments was a mongrel male obtained from the Yokohama dog pound. The animal was approximately three years of age, and weighed 51 pounds at the beginning of the study. In spite of a rather high microfilarial count the dog was in good physical condition.

Blood for microfilarial counts was drawn from the radial vein of the forelimb between 1300-1330 hours on the day of examination. Counts were made of microfilariae in each of two wet preparations of $20 \mathrm{cmm}$. Microfilarial counts for this animal prior to treatment varied between $50-75 \mathrm{mf} / 20 \mathrm{cmm}$ of blood. Counts were made on the day the blood was drawn, and on the day mosquitoes were fed on the animal.

The filaricide used in treatment of this dog was a commercially produced preparation containing diethylcarbamazine as the active ingredient. The minimum effective dose recommended by the manufacturer was administered. This was $30 \mathrm{mg} / 1 \mathrm{~b}$ body weight daily for 21 days. The daily medication was given in three equal doses orally at 0800,1200 , and 1600 hours. The microfilarial count recorded each day was the mean of the counts from the two $20 \mathrm{cmm}$ preparations.

Specimens of Aedes togoi of 5-10 postemergence days in age were allowed to feed on the treated dog in the manner previously described.
Aedes togoi was chosen for this test because of high infectivity rates obtained in earlier studies. This mosquito is found in Japan, Korea, Northern China and Siberia and in some areas have been suspected as a vector of human filariasis.

During April and May of 1966 a field survey of incidence of $D$. immitis microfilaremia in dogs, and of $D$. immitis larvae in wildcaught mosquitoes was carried out at Kochi City, Shikoku and adjacent areas. This region was chosen because preliminary studies in Octoter, 1965 had shown that Aedes togoi, which had been reported by Inoue (1937) and Kume (1958) as a highly receptive host for $D$. immitis, was numerous in the area and because spring weather conditions were more suitable for mosquito surveys in this area that in the Kanto plain.

Dogs examined during the survey were from three main sources : (1) kennel dogs (commercial or fighting); (2) privately owned dogs kept at residences, and (3) dogs in an animal shelter at Kochi. Some of the privately owned animals were from the sea-side area; some from in and around Kochi City, and others from nearby wooded foothills.

Data recorded for each dog included physical description (particularly with respect to hair length) age, sex, past history of infection, and for privately owned animals, information as to whether the dog was allowed to run free at any time of the day or was kept outdoors or inside the house at night.

\section{RESUlTS AND DisCUSSION}

Results of experimental feedings of mosquitoes on an infected $\mathrm{dog}$ are summarized in Table 1. The evident superiority of Aedes togoi as a host is not surprising in view of similar results obtained by Inoue (1937). This mosquito was also described as a suitable host for D. immitis by Kume (1958), who used it for production of infective $D$. immitis larvae for his studies of prophylactic therapy against Dirofilaria infection in dogs. Results obtained by other workers with Aedes aegypti and Culex fatigans have shown considerable variation. Although Rosaria (1936) found C. fatigans in Manila highly susceptible to infection, and Travis (1947) reported an experimental infection rate of $23 \%$ in C. fatigans on Guam, Rosen (1954) wrote that, although some larvae of $D$. 
Table 1 Occurrence of Dirofilaria immitis larvae in mosquitoes of eight species dissected 12 days following a blood meal on an infected dog

\begin{tabular}{|c|c|c|c|c|c|}
\hline Species & $\begin{array}{l}\text { No. } \\
\text { examined }\end{array}$ & $\begin{array}{l}\text { No. } \\
\text { negative }\end{array}$ & $\begin{array}{c}\text { No. with } \\
\text { non-infective } \\
\text { larvae only }\end{array}$ & $\begin{array}{c}\text { No. with both } \\
\text { non-infective and } \\
\text { infective larvae }\end{array}$ & $\begin{array}{c}\text { No. with } \\
\text { infective larvae } \\
\text { only }\end{array}$ \\
\hline \multicolumn{6}{|l|}{ Aedes } \\
\hline albopictus & 64 & 63 & 0 & 0 & 1 \\
\hline aegypti & 92 & 73 & 7 & 3 & 9 \\
\hline togoi & 107 & 3 & 1 & 22 & 81 \\
\hline \multicolumn{6}{|l|}{ Culex } \\
\hline fatigans & 36 & 35 & 0 & 0 & 1 \\
\hline pipiens pallens & 33 & 32 & 0 & 0 & 0 \\
\hline $\begin{array}{l}\text { tritaeniorhynchus } \\
\text { Armigeres }\end{array}$ & 144 & 139 & 2 & 2 & 1 \\
\hline $\begin{array}{l}\text { subalbatus } \\
\text { Anopheles }\end{array}$ & 12 & 12 & 0 & 0 & 0 \\
\hline sinensis & 9 & 0 & 9 & 0 & 0 \\
\hline
\end{tabular}

immitis completed development in C. fatigans in the laboratory, only one of more than 1,000 wild caught fatigans in a highly endemic area in French Oceania was infected. This single specimen harbored immature larvae. While Rosario (1936) also reported that Aedes aegypti in Manila was quite susceptible to infection, Travis (1947) found that only two percent of aegypti allowed to feed on an infected dog developed infective stage larvae. Kartmann (1953) infected both aegypti and fatigans during his studies of factors affecting infection of mosquitoes with immitis, and concluded that aegypti is a generally refractory host for $D$. immitis, but that in some regions there are specially susceptible individuals from which, through a process of selection, a population may arise that shows a superior host efficiency and a high incidence of infection.

Studies to determine the relative effectiveness as hosts for $D$. immitis of $A$. togoi of different age groups were undertaken because of the work of Duxbury, Moon, and Sadun (1961). These workers found that more larvae of a related species, Dirofilaria uniformis, developed in specimens of Anopheles quadrimaculatus 12-13 days old than in mosquitoes 4-5 days old. Similarly, Desowitz and Cellapah (1962) maintained that in dealing with Brugia sp. in Culex fatigans, the older the mosquito the better it was as a host. Jordon, however, (1962) who questioned these previous findings, found no significant differences in numbers of Wuchereria bancrofti larvae in Culex fatigans of different age groups, provided that all third-stage larvae present were counted-not just those in the proboscis.

While our results, shown in Table 2 , clearly demonstrate high infectivity of $D$. immitis for mosquitoes in each of the four age groups tested, the small numbers of mosquitoes involved necessitate caution in predicting which of the four age groups involved would actually be most effective as hosts for $D$. immitis.

Fluctuations in microfilaria density per 20 $\mathrm{cmm}$ of blood of a dog during a 21 day period of treatment with a filaricidal drug are shown in Figure 1. The same figure shows fluctuations in numbers of infective larvae of $D$. immitis developing in mosquitoes, Aedes togoi, fed on the dog on ten of the days during the period of treatment. This study was undertaken to determine whether microfilariae in peripheral blood of a dog under treatment with a filaricidal drug would remain infective for mosquitoes, or whether, as reported by Manson (1952) during his work with Wuchereria bancrofti in the Fiji Islands, treatment of the host would so modify the microfilariae that they would lose capability of normal development in the mosquito.

Our results were much like those of Rosen (1955) who reported that $W$. bancrofti microfilariae from the blood of persons previously treated with Hetrazan developed as readily in Aedes polynesiensis as did microfilariae from blood of untreated individuals. 
Table 2 Location and numbers of infective Dirofilaria immitis larvae in experimentally infected mosquitoes, Aedes togoi, of four age groups*

\begin{tabular}{l|c|c|c|c}
\hline \hline & \multicolumn{4}{|c}{ Age Groups } \\
\cline { 2 - 5 } & $5-7$ days & $10-12$ days & $15-17$ days & $20-22$ days \\
\hline No. examined & 26 & 55 & 21 & 5 \\
No. infected & 25 & 53 & 21 & 5 \\
Average No. larvae/mosquito in : & & & & \\
$\quad$ labium & 6.85 & 8.69 & 10.60 & 5.00 \\
$\quad$ Malpighian tubules & 0.42 & 0.27 & 1.53 & 0.40 \\
$\quad$ haemocoele & 5.38 & 1.95 & 5.48 & 1.00 \\
Total : Average No. & 12.65 & 10.91 & 16.61 & 6.40
\end{tabular}

* Days after emergence from pupal stage.

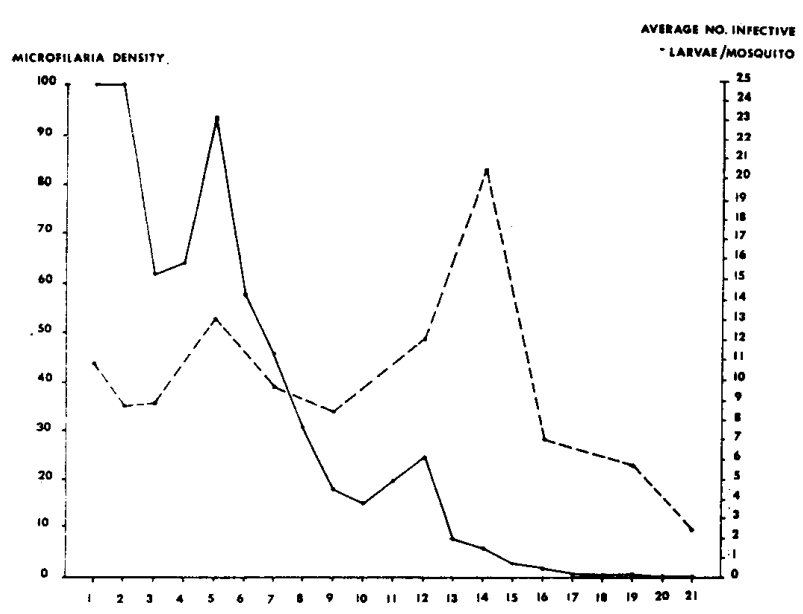

Fig. 1. Fluctuation in Dirofilaria immitis microfilaria density in a dog under treatment with a filaricidal drug during a 21 day period, and in numbers of infective immitis larvae developing in mosquitoes, Aedes togoi, fed on the dog on 10 days during the same period. The microfilaria density is expressed as per cent of the count on the day treatment was started. This was $650 \mathrm{mf} /$ $20 \mathrm{cmm}$. of blood. The infective larva count is expressed as the average number of infective larvae found in mosquitoes fed on the dog on each day indicated and examined 12 days thereafter.

Although the dog at first seemed to tolerate the drug well, it became ill on the third day of treatment and regurgitated the medication. This was responsible for the abrupt rise in microfilaria density shown in Figure 1 for days 4 and 5 . Failure of the infective larval count in mosquitoes to decline proportionately with the microfilaria density was not unexpected. Hawking and Worms (1961) reviewed studies of the quantitative relationships between the number of microfilariae in the blood and the number taken up by the vector. They sum. marized that the actual uptake is extremely variable, and is usually less than might have been expected from the volume of blood ingested, although Culex fatigans, feeding on patients with $W$. bancrofti in Malaya seemed to take up three times as many microfilariae as would have been expected from their blood meal. They concluded that there was no evidence of a chemotropic factor whith attracts microfilariae to the bite. In instances where mosquitoes ingested less microfilariae than might have been expected, they theorized that this might be caused by a variation in the number of microfilariae present in individual cutaneous capillaries, or to feeding of mosquitoes from a pool of blood which was escaping from capillaries, the erythrocytes escaping more rapidly than microfilariae. After the 13th day of medication it was much easier to demonstrate infection in the mosquitoes than in the dog. The infectivity of very small numbers of $D$. immitis microfilariae for mosquitoes could be of considerable practical importance in control efforts. Hawking and Worms (1961) described a similar situation in which Aedes polynesiensis were fed on $W$. bancrofti patients with a microfilaria density of only one microfilaria/ $50 \mathrm{cmm}$ of blood. About five percent of these mosquitoes became infected, each mosquito containing only a single larva. Similarly, $10 \%$ of specimens of Mansonia longipalpis fed on patients with only one microfilariae $/ 40 \mathrm{cmm}$ of blood became infected. Each of these mosquitoes harbored only one infective larva. Rosen (1955) concluded that any density of microfilariae likely to be detected on the examination of a single specimen of 20 
cmm of blood was infective for Aedes polynesi. ensis.

Although the dog used in our feeding experiments lost 13 pounds during the first five days of treatment, it showed gradual improvement in its physical condition, and no further weight loss following its illness on the third day of treatment. Survival rates of mosquitoes fed on the dog during treatment days 1-7 varied between $60-80 \%$. It dropped to $38 \%$ among mosquitoes fed on the dog on the ninth treat- ment day, but thereafter rose gradually. The survival rate was $100 \%$ among mosquitoes fed on the dog two days following termination of treatment.

Results of microfilaremia surveys among dogs at Kochi, Shikoku and vicinity are shown in Tables 3-6. Although data obtained were grouped according to nature of the "housing" of dogs examined, and according to the degree of restraint to which they were subjected, the only factor, other than age, which showed a

Table 3. Dirofilaria immitis microfilaremia in dogs of four age groups in the vicinity of Kochi, Shikoku, Japan

\begin{tabular}{c|c|c|c}
\hline Age in years & No. examined & No. infected & \% infected \\
\hline 1 & 7 & 0 & 0.0 \\
1 and 2 & 69 & 8 & 11.6 \\
3, 4, and 5 & 57 & 13 & 22.8 \\
6 and over & 29 & 15 & 51.8 \\
\hline Totals : & 162 & 36 & 22.2
\end{tabular}

Note: Data given above were obtained by questioning owners.

Eight of 41 dogs $(19.5 \%)$ of undetermined age and origin from the Kochi dog pound were infected.

Table 4. Dirofilaria immitis microfilaremia among 162 dogs from three habitats at Kochi, Shikoku, Japan

\begin{tabular}{l|c|c|c}
\hline \multicolumn{1}{c|}{ Habitats* } & \multicolumn{2}{|c}{ Dog examinations } \\
\cline { 2 - 4 } & No. examined & No. with microfilaremia & \% with microfilaremia \\
\hline Seaside & 52 & 5 & 9.6 \\
Urban Kochi & 56 & 7 & 12.5 \\
Wooded suburban foothills & 54 & 24 & 44.5
\end{tabular}

Note: The seaside area was 1,000-2,500 meters from urban Kochi. The wooded suburban foothills were 7,000-10,000 meters from urban Kochi. The average age in years of dogs at the seaside in urban Kochi and in the suburban foothill area was 4.2, 3.7, and 3.9 respectively.

Table 5. Dirofilaria immitis microfilaremia among 203 dogs of fcur categories with respect to housing at Kochi, Shikoku, Japan

\begin{tabular}{l|c|c|c}
\hline & \multicolumn{2}{|c}{ Dog examinations } \\
\cline { 2 - 4 } & No. examined & No. with microfilaremia & \% with microfilaremia \\
\hline Dog house & 73 & 16 & 21.9 \\
$\begin{array}{l}\text { Kennel (commercial or private } \\
\text { but at least withseveral dogs) }\end{array}$ & 53 & 12 & 22.2 \\
Owner's home & 28 & 6 & 21.4 \\
No home (pound dogs) or & 49 & 10 & 20.4
\end{tabular}

Note: Several of the animals were fighting dogs raised specifically for this sport, which is popular in the Kochi area. 
Table 6. Incidence of Dirofilaria immitis microfilaremia among dogs subjected to varying degrees of restraint at Kochi, Shikoku, Japan

\begin{tabular}{l|r|r|r}
\hline \multirow{2}{*}{ Degrees of restraint } & \multicolumn{2}{|c}{ Results of dog examinations } \\
\cline { 2 - 4 } & No. examined & No. with microfilaremia & \% with microfilaremia \\
\hline Allowed to run free & & & 0.0 \\
Daytime orly & 5 & 2 & 25.0 \\
Nighttime only & 8 & 11 & 17.0 \\
Day and night & 62 & 31 & 24.2
\end{tabular}

high degree of correlation with microfilaremia incidence was habitat. The relatively kigh incidence $(44.5 \%)$ of infected dogs in the wooded foothill area was in marked contrast to the much lower rates found in the two other habitats. This undoubtedly reflects the greater abundance and variety of mosquito vectors in the foothill area. Although Lindsey (1961) found that prevalence of $D$. immitis did not vary according to sex or hair length of dogs examined, Wallenstein and Tibola (1960) had found immitis infections in male dogs four times as frequently as in females.. In our own survey $27(28.2 \%)$ of 96 male dogs examined were infected, while only $17(15.9 \%)$ of 107 female dogs were parasitized. Seven $(14.0 \%)$ of 50 long haired dogs were infected, and $37(24.2 \%)$ of 153 short haired dogs were positive for immitis microfilaremia.

Dissection and examination of 1,813 adult mosquitoes of seven species obtained in light traps, and in resting and biting collections in the vicinity of dog kennels was rather unrewarding as only eight infected mosquitoes were found. These results are summarized in Table 7.

The most prevalent mosquito in harıd and light trap collections in the seaside area was Culex fatigans. Four $(0.62 \%)$ of the 649 specimens dissected in this area contained $D$. immitis larvae. In three of these specimens infective larvae of immitis were present in the labium. One mosquito contained four larvae, one two, and the third a single larva. The fourth positive specimen contained two early third stage larvae.

Other adult mosquitoes collected and examined in this area were Armigeres subalbatus (84); Anopheles sirensis (41); Anopheles sineroides (1); and Aedes togoi (10). None of these was infected. In the beach area numerous larvae of Culex fatigans were found in man-made containers such as tin cans, water storage tanks, and manure pits. Armigeres subalbatus larvae were also found in manure pits. A few Aedes togo $i$ larvae were found in a water container about 1,000 meters from the shore. A single C. tritaeniorhynchus larva was also found in this area.

Light trap, and resting and biting collections of adult mosquitoes in urban Kochi yielded 219 specimens of Culex fatigans, 22 of Anopheles sinensis, 1 of Anopheles sineroides and 31 of

Table 7. Occurrence of third stage larvae of Dirofilaria immitis in mosquitoes of seven species at Kochi, Shikoku, Japan

\begin{tabular}{l|c|c|c}
\hline \hline \multicolumn{1}{c|}{ Species } & No. examined & No. positive & positive \\
\hline Culex fatigans & 982 & 5 & 0.51 \\
Culex tritaeniorhynchus & 43 & 0 & 0.00 \\
Armigeres subalbatus & 140 & 0 & 0.00 \\
Aedes albopictus & 99 & 0 & 0.00 \\
Aedes togoi & 349 & 3 & 0.86 \\
Anopheles sinensis & 197 & 0 & 0.00 \\
Anopheles sineroides & 3 & 0 & 0.00 \\
\hline Total & 1,813 & 8 &
\end{tabular}


Aedes albopictus. One of the $C$. fatigans examined contained two infective immitis larvae in the labium. All other mosquitoes examined were negative. Culex fatigans larvae were abundant in a variety of man-made containers in urban Shikoku.

Adults of seven species of mosquitoes were collected in the wooded foothill area 7,00010,000 meters from urban Kochi. The included Culex fatigans (114); C. tritaeniorhynchus (43); Armigeres subalbatus (56); Aedes togoi (339); Aedes albopictus (68); Anopheles sinensis (134); and Anopheles sineroides (1). This was the only area in which Aedes togoi was the most abundant species taken. Three of the $A$. togoi contained infective larvae of $D$. immitis. One specimen contained 17 infective larvae in the labium, two in the head capsule, and one early third stage larva in the Malpighian tubules. The second positive mosquito contained a single infective stage larva in the labium. The third contained four infective larvae in the labium. The stomach of one of 24 recently engorged Culex fatigans collected in the area contained seven living microfilariae. All other mosquitoes were negative.

Throughout the foothill area Aedes togoi larvae were numerous in water containers, together with larvae of $C$. fatigans. Larvae of Anopheles sinensis were numerous in rice paddies in the area. Armigeres subalbatus larvae were found in polluted water in many places.

Apparently little has been published concerning incidence of $D$. immitis larvae in wild caught mosquitoes. In his surveys in French Oceania Rosen (1954) found infective stage larvae of immitis in only two of 2,390 specimens of Aedes polynesiensis and eight of his 446 Culex annulirostris captured near animal shelters in a region of high ( $40 \%$ ) endemicity for dirofilariasis. None of 1,061 Culex fatigans examined by him was infected. A somewhat higher percentage of infected wild caught mosquitoes was reported by Phillips (1939) who found four of 21 Anopheles punctipennis, 2 of 10 Anopheles quadrimaculatus, and a single Aedes excrucians taken with sausage-shaped larvae of $D$. immitis in the Malpighian tubules. These mosquitoes were collected in unscreened kennels harboring infected dogs. After the dogs were removed, no further mosquitoes were found.

\section{SUMMARY}

1. Tests were conducted to determine susceptibility of eight species of mosquitoes to infection with microfilariae of Dirofilaria immitis. Highest infection rates and largest numbers of infective larvae were found in specimens of Aedes togoi fed on an infected dog and examined 12 days thereafter. Other species tested were Culex pipiens fatigans, Culex pipiens pallens, Culex tritaeniorhynchus, Aedes albopictus, Aedes aegypti, Armigeres subalbatus, and Anopheles sinensis.

2. There were no outstanding differences in $D$. immitis infection rates among Aedes togoi of four age groups allowed to feed on an infected dog.

3. Microfilariae in peripheral blood of a dog under treatment for dirofilariasis during a 21 day period remained infective for mosquitoes, Aedes togoi, fed on the dog on 10 days during the course of treatment. Decline in numbers of microfilariae in blood of the dog was much more rapid than decline in numbers of infective immitis larvae in mosquitoes which had been fed on the dog and dissected 12 days thereafter.

4. In surveys of microfilaremia among dogs at Kochi, Shikoku the factors which showed most striking correlation with high incidence of infection with $D$. immitis were age and habitat. Dogs from wooded foothills outside Kochi City proper showed a much higher microfilaremia rate than those from urban Kochi and from a seaside area near the city. Short haired dogs showed an infection rate nearly twice that of long haired animals, and males were infected nearly twice as frequently as females.

5. Only eight of 1,813 adult female mosquitoes of seven species obtained in light traps, and in resting and biting collections in the vicinity of dog kennels at the seaside, urban Kochi, and wooded suburban foothills 7,00010,000 meters from urban Kochi were infected with larvae of Dirofilaria immitis. Five of these were specimens of Culex fatigans, the remaining three were examples of Aedes togoi. Four of the infected C. fatigans were collected at the seaside area, and one was found in urban Kochi. The three infected specimens of Aedes togoi were found in the wooded foothills, the 
only area where this mosquito was most numerous.

\section{REFERENCES}

1) Desowitz, R. S. and Chellapah, W. T. (1962): The transmission of Brugia sp. through Culex pipiens fatigans: the effect of age and prior non-infective blood meals in the infection rate. Trans. R. Soc. Trop. Med. Hyg., 56 : 121-125. -- 2) Duxbury, R. E., Moon, A. P. and Sugun, E. H. (1961): Susceptibility and resistance of Anopheles quadrimaculatus to Dirofilaria uniformis. J. Parasit., 47: 687-692. - 3) Hawking, F. and Worms, M. (1961): Transmission of filarioid nematodes. Ann. Rev. Entomol., 6 : 413-432. -4) Inoue, T. (1937) : Development of Dirofilaria immitis in nine species of mosquitoes in Tokyo. Keio Igaku, 17 (6) : 10971128. - 5) Jordan, P. (1962): Transmission of Brugia through C. pipiens fatigans. (Correspondence) Trans. R. Soc. Trop. Med. Hyg., 56 : 436. -6) Kartman, L. (1953): Factors influencing infection of the mosquito with Dirofilaria immitis (Leidy, 1856). Exptl. Papasit., 2 : 27-78. -7) Kume, S. (1958): Prophylactic therapy against the developing stages of Dirofilaria immitis before reaching the canine heart. Am. J. Vet. Res. - 8) Lindsey, J. R. (1961) : Diagnosis of filarial infections in dogs. I. Microfilarial surveys. J. Parasit., 47: 695-702. -9) Manson-Bahr, P. (1952) : Further research on filariasis in Fiji. Jour. Trop. Med. and Hyg., 55 : 169-173. - 10) Marquardt, W. C, and Fabian, W. E. (1966): The distribution in
Illinois of filariids of dogs. J. Parasit., $52(2): 318-$ 322. - 11) Phillips, J. H. (1939): Studies on the transmission of Dirofilaria immitis in Massachusetts. Amer. J. Hyg., 29 : 121-129. - 12) Rosario, F. del (1936) : Dirofilaria immitis Leidy and its culicine hosts in Manila, P. I. Philip. J. Sci., 60: 45-47. - 13) Rosen, L. (1954): Observations on Dirofilaria immitis in French Oceania. Ann. Trop. Med. Parasit., 48 : 318-328. - 14) Rosen, L. (1955) : Observations on the epidemiology of human filariasis in French Oceania. Amer. J. Hyg., 61 : 219-248. -15) Travis, B. V. (1947) : Relative efficiency of six species of mosquitoes from Guam, M. I. as developmental hosts for Dirofilaria immitis. J. Parasit., 33 : 142-145. - 16) Wallenstein, W. L. and Tibola, B. J. (1960) : Survey of canine filariasis in a Maryland area -incidence of Dirofilaria immitis and Dipetalonema. J. Am. Vet. Med. As., 137 : 712-716.

\section{摘要 \\ 日本における犬糸状虫についての 室内実験および野外実験}

井上 (1937) は Dirofilaria immitis の中間宿主とし てAedes togoi の重要性を報告した。この研究は彼の 結果を追試するために行な扎机た。 そして, 井上が報告 する如く Aedes togoi が供試した蚁の中では最上位を しめし，この関係嚆知における野外試験での結果にお いても同じである. 